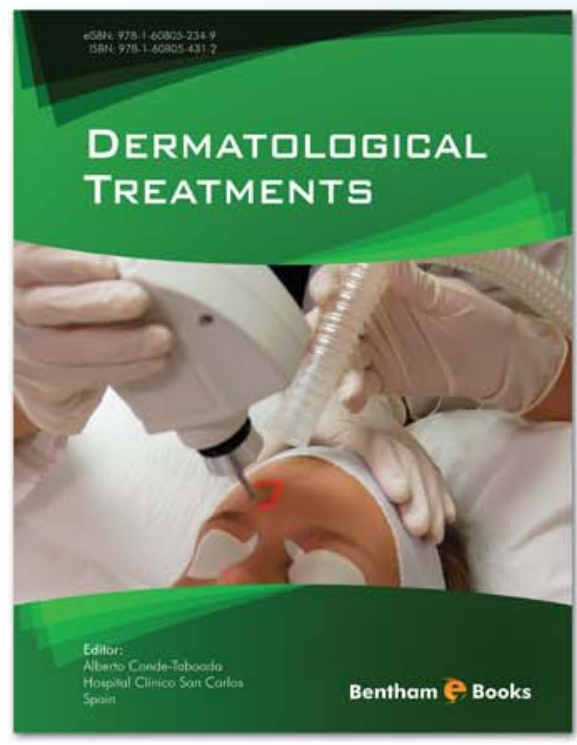

Editor:

Alberto Conde-Taboada Spain

\title{
USS
}

\section{Dermatological Treatments}

\section{Ww.Lenthamseience.com/ehooks/9781608052349}

\section{About the ebook}

This e-book is comprised of 3 sections, based on the way the treatment is applied: topical treatments, systemic treatments and physical therapies. Specific emphasis is given to the practical usage of each drug with comprehensive tables facilitating the information.

\section{Contents}

Basics of Topical Therapy

- Moisturizing and Keratolytic Agents

- Topical Corticosteroids

- Topical Antimicrobials

- Topical Retinoids

- Topical Immunomodulators

- Systemic Corticosteroids

Systemic Antimicrobials: Antibiotics, Antifungals, Antivirals, Antiparasitics

For Sales and Advertising Inquiries: Contact: marketing@benthamscience.org 